\title{
Protection from Noise-Induced Hearing Loss by Kv2.2 Potassium Currents in the Central Medial Olivocochlear System
}

\author{
Huaxia Tong, ${ }^{1 \star}$ Cornelia Kopp-Scheinpflug, ${ }^{1 \star}$ Nadia Pilati, ${ }^{2}$ Susan W. Robinson, ${ }^{1}$ James L. Sinclair, ${ }^{2}$ Joern R. Steinert, ${ }^{1}$ \\ Margaret Barnes-Davies, ${ }^{2,3}$ Rebecca Allfree, ${ }^{2,3}$ Blair D. Grubb, ${ }^{2}$ Samuel M. Young Jr, ${ }^{4}$ and Ian D. Forsythe ${ }^{2}$ \\ ${ }^{1}$ Neurotoxicity at the Synaptic Interface, Medical Research Council Toxicology Unit, and Departments of ${ }^{2}$ Cell Physiology and Pharmacology, and ${ }^{3}$ Medical \\ and Social Care Education, University of Leicester, Leicester LE1 9HN, United Kingdom, and ${ }^{4}$ Research Group Molecular Mechanisms of Synaptic Function, \\ Max Planck Florida Institute, Jupiter, Florida 33458
}

The central auditory brainstem provides an efferent projection known as the medial olivocochlear (MOC) system, which regulates the cochlear amplifier and mediates protection on exposure to loud sound. It arises from neurons of the ventral nucleus of the trapezoid body (VNTB), so control of neuronal excitability in this pathway has profound effects on hearing. The VNTB and the medial nucleus of the trapezoid body are the only sites of expression for the Kv2.2 voltage-gated potassium channel in the auditory brainstem, consistent with a specialized function of these channels. In the absence of unambiguous antagonists, we used recombinant and transgenic methods to examine how Kv2.2 contributes to MOC efferent function. Viral gene transfer of dominant-negative Kv2.2 in wild-type mice suppressed outward $\mathrm{K}^{+}$currents, increasing action potential (AP) half-width and reducing repetitive firing. Similarly, VNTB neurons from Kv2.2 knock-out mice (Kv2.2K0) also showed increased AP duration. Control experiments established that Kv2.2 was not expressed in the cochlea, so any changes in auditory function in the Kv2.2K0 mouse must be of central origin. Further, in vivo recordings of auditory brainstem responses revealed that these Kv2.2KO mice were more susceptible to noise-induced hearing loss. We conclude that Kv2.2 regulates neuronal excitability in these brainstem nuclei by maintaining short APs and enhancing high-frequency firing. This safeguards efferent MOC firing during high-intensity sounds and is crucial in the mediation of protection after auditory overexposure.

\section{Introduction}

Central neurons express many different potassium channels that act together with other ion channels to determine resting membrane potentials, action potential (AP) firing thresholds, and AP waveform. Understanding the rules governing the expression of particular families or subunits and their physiological roles is complicated by the large number of different $\mathrm{K}^{+}$channel genes, their heterogenic expression, physical location, and modulatory mechanisms such as phosphorylation (Rasband, 2004; Johnston et al., 2010; Turrigiano, 2011). Here we focus on Kv2.2, which has

Received 0ct. 29, 2012; revised April 12, 2013; accepted April 17, 2013.

Author contributions:C.K.-S., M.B.-D., B.D.G., and I.D.F. designed research;H.T., C.K.-S., N.P., S.W.R., J.L.S., J.R.S., and R.A. performed research; S.M.Y. contributed unpublished reagents/analytic tools; H.T., C.K.-S., and N.P. analyzed data; H.T., C.K.-S., B.D.G., S.M.Y., and I.D.F. wrote the paper.

This work was supported by the Medical Research Council UK, Deafness Research UK and AgeUK, Action on Hearing Loss, and the Max Planck Society, Germany. We thank the Wellcome Trust Knockout Mouse Resource Committee for funding the Kv2.2 knockout mouse; and Martine Hamann and Michael Mulheran for setting up the ABR measurement.

*H.T. and C.K.-S. are joint first authors.

This article is freely available online through the J Neurosci Author Open Choice option.

Correspondence should be addressed to lan D. Forsythe, Department of Cell Physiology and Pharmacology, University of Leicester, Leicester LE1 9HN, United Kingdom. E-mail: idf@le.ac.uk.

H. Tong's present address: Department of Biology, University of Leicester, LE1 7RH Leicester, United Kingdom.

C. Kopp-Scheinpflug's present address: Division of Neurobiology, Department Biology II, Ludwig-MaximiliansUniversity Munich, D-82152 Planegg-Martinsried, Germany.

DOI:10.1523/JNEUROSCI.5043-12.2013

Copyright $\odot 2013$ the authors $\quad 0270-6474 / 13 / 339113-09 \$ 15.00 / 0$ a highly selective expression in the auditory brainstem. The other family member, Kv2.1, is abundant in the neocortex (Guan et al., 2007) and hippocampus (Murakoshi and Trimmer, 1999) and is rarely coexpressed with Kv2.2 (Malin and Nerbonne, 2002; Kihira et al., 2010). Both subunits form heteromeric channels with the accessory subunit families Kv5, Kv6, and Kv9 (Coetzee et al., 1999). Kv2.2 has a more restricted expression in the olfactory bulb (Eyre et al., 2009), preoptic areas (Hermanstyne et al., 2010), and auditory brainstem (Johnston et al., 2008) and lesser expression in the cortex (Guan et al., 2007, Kihira et al., 2010). The rather precise expression of Kv2.2 in just two nuclei of the auditory brainstem, the medial and ventral nuclei of the trapezoid body (MNTB and VNTB, respectively), presents an opportunity to study its function at a cellular and physiological level. The MNTB is a well characterized, glycinergic relay nucleus involved in the binaural circuits underlying sound source localization (Johnston et al., 2010) and it expresses voltage-gated $\mathrm{K}^{+}$channels from all of the four major families, each with specific roles in regulating AP threshold, waveform, and timing (Brew and Forsythe, 1995; Wang et al., 1998; Kopp-Scheinpflug et al., 2003; Kaczmarek et al., 2005; Johnston et al., 2010; Tong et al., 2010; Karcz et al., 2011). The VNTB provides an efferent projection via the olivocochlear bundle to outer hair cells (OHCs) in the cochlea as part of the medial olivocochlear (MOC) system (Brown and Levine, 2008). The cholinergic projection acts via nicotinic $(\alpha 9)$ receptors to suppress electromotility of the OHCs and to raise 
inner hair cell (IHC) thresholds during loud sounds (Brown and Nuttall, 1984; Elgoyhen et al., 1994), which suggests a role for Kv2.2 in the integration of central auditory inputs for efferent feedback to the cochlea and hence in protection from sound trauma.

We have taken a molecular approach, using overexpression of Kv2.2 mutations that do not conduct $\mathrm{K}^{+}$ions (dominantnegative, DN), deletion in a transgenic mouse (Kv2.2 knock-out, Kv2.2KO), and rescue by transfection of Kv2.2 wild-type (WT). Whole-cell patch recordings from MNTB neurons identified a broad physiological role for Kv2.2 currents in regulating neuronal excitability, demonstrating that it complements Kvl and assists Kv3 currents in determining AP half-width. In the VNTB, Kv2.2 maintains AP firing during sustained afferent activity. In vivo recording showed that Kv2.2 expression is necessary for the protective function of the MOC system during exposure to loud sounds. Deletion of Kv2.2 reduced recovery from acoustic overexposure (AOE), suggesting that targeting Kv2 channels may provide a therapeutic strategy for protection during exposure to loud sounds.

\section{Materials and Methods}

Animals. All animal experiments were performed in accordance with the UK Animals (Scientific Procedures) Acts of 1986 and 2012. CBA/Ca mice served as our control strain and the Kv2.2KO mice were backcrossed onto this strain for these experiments. Kv2.2KO mice were purchased under the Wellcome Trust scheme (2H-2007 Project) from Lexicon (LEXCO 1551, kcnb2) via cryopreservation at the EMMA GSF (National Research Center for Environment and Health, Neuherberg, Germany).

Brain slice preparation. For preparation of slices mice aged P13-P21 and of either sex were killed by decapitation, and brainstem slices containing the MNTB and VNTB were prepared as described previously (Barnes-Davies and Forsythe, 1995). In brief, transverse slices of the SOC were cut in an ice-cold $\left(<4^{\circ} \mathrm{C}\right)$ low-sodium aCSF. For the experiments shown in Fig. $2 a, b$, brainstem slices were used instantly after slicing to avoid $\mathrm{Kv}$ current rundown during incubation; otherwise, slices were incubated at $\sim 37^{\circ} \mathrm{C}$ for $1 \mathrm{~h}$ in normal aCSF, after which they were stored at room temperature $\left(\sim 20^{\circ} \mathrm{C}\right)$ in a continually recycling slice-maintenance chamber. Composition of the normal aCSF was as follows (in mM): 125 $\mathrm{NaCl}, 2.5 \mathrm{KCl}, 26 \mathrm{NaHCO}_{3}, 10$ glucose, $1.25 \mathrm{NaH}_{2} \mathrm{PO}_{4}, 2$ sodium pyruvate, 3 myoinositol, $2 \mathrm{CaCl}_{2}, 1 \mathrm{MgCl}_{2}$, and 0.5 ascorbic acid, $\mathrm{pH} 7.4$, continuously bubbled with $95 \% \mathrm{O}_{2} / 5 \% \mathrm{CO}_{2}$. In the low-sodium aCSF, $\mathrm{NaCl}$ was replaced by $250 \mathrm{~mm}$ sucrose, $0.1 \mathrm{mM} \mathrm{CaCl}_{2}$, and $4 \mathrm{~mm} \mathrm{MgCl}_{2}$. All chemicals were obtained from Sigma unless otherwise noted.

Electrophysiology. For recordings, a slice was transferred to a Peltiercontrolled environmental chamber $\left(37 \pm 1^{\circ} \mathrm{C}\right)$ on the stage of a Zeiss Axioskop/Nikon FN600 microscope. Individual cells were visualized using differential interference contrast optics and $63 \times(0.9$ numerical aperture) water-immersion objectives.

Whole-cell patch-clamp recordings were made using a Multiclamp 700B amplifier (Molecular Devices) and pClamp 9.2 software (Molecular Devices), sampling at $50 \mathrm{kHz}$ and filtering at $10 \mathrm{kHz}$. Patch pipettes were pulled from filamented borosilicate glass (GC150F-7.5; Harvard Apparatus) using a two-stage vertical puller (PC-10; Narishige). Pipettes (3-4 $\mathrm{M} \Omega$ ) were filled with a solution containing the following (in $\mathrm{mM}$ ): 97.5 K-gluconate, $32.5 \mathrm{KCl}$, 40 HEPES, 5 EGTA, $1 \mathrm{MgCl}_{2}, 5 \mathrm{Na}_{2}$ phosphocreatine, $\mathrm{pH} 7.2$ with $\mathrm{KOH}$. Whole-cell access resistance was $<10 \mathrm{M} \Omega$ and series resistance was routinely compensated by $70 \%$. A -11 $\mathrm{mV}$ junction potential was subtracted from all current-voltage (I/V) curves.

Creation of Kv2.2DN/Kv2.2WT-containing virus. Mouse Kv2.2 cDNA carrying the DN mutations at amino acid position $373 \mathrm{~W} \rightarrow \mathrm{C}$ and 388 $\mathrm{Y} \rightarrow \mathrm{T}$ was codon optimized for expression in mouse (Geneart). To create the WT version of the Kv2.2 cDNA, amino acid 373 was converted $\mathrm{C} \rightarrow \mathrm{W}$ and 388 was converted $\mathrm{T} \rightarrow \mathrm{Y}$. This was performed by two subcloning steps involving PCR cloning using the oligos 5' GTGGGCCACCATCACCATGAC $3^{\prime}$ and 5' CAAAAGCTGGCGGGGATGGAG $3^{\prime}$ in and
5' TACCCCAAGACCCTGCTGGGC 3' 5' GATGTCGCCGTAGCCCA CGGT 3'. Afterward, cDNA of both Kv2.2WT and Kv2.2DN was cloned into the pUNISHER expression cassette (Young and Neher, 2009). The second-generation E2a deleted adenoviruses that allowed for neurospecific expression of EGFP in conjunction with the Kv2.2WT or Kv2.2DN were made as described previously (Young and Neher, 2009; Montesinos et al., 2011). Recombinant adenovirus ( $\mathrm{rAd}$ ) was produced using the standard protocol (Malin and Nerbonne, 2002) and stored in $10 \mathrm{~mm}$ HEPES, $250 \mathrm{~mm}$ sucrose, and $1 \mathrm{~mm} \mathrm{MgCl}_{2}$ at $\mathrm{pH}$ 7.4.

Characterization of recombinant Kv2.2 channels in Neuro-2a cells. Endogenous voltage-dependent $\mathrm{K}^{+}$conductance is absent in the Neuro-2a cell line (Garcia-Guzman et al., 1992), which made it an ideal system with which to characterize the recombinant Kv2.2 channels. Neuro-2a cells were infected with rAd Kv2.2DN $\left(1.25 \times 10^{9}\right.$ particles/ml $)$ or Kv2.2WT $\left(1.1 \times 10^{9}\right.$ particles/ml). EGFP-labeled cells were found at $24 \mathrm{~h}$ after infection, and these experiments were performed $48 \mathrm{~h}$ after infection at room temperature.

Animal surgery. CBA or Kv2.2KO mice (P13-P16) were anesthetized in a Plexiglas chamber with $5 \%$ isofluorane mixed with $95 \% \mathrm{O}_{2}$. Once the pedal reflex had gone, the mouse was placed on a heating pad and its skull secured in a stereotactic frame (David Kopf). A mask was placed over the animal's mouth and nose and the animal was ventilated with $1.5-2.5 \%$ isoflurane in $95 \% \mathrm{O}_{2}$ to maintain anesthesia. The top of the head was cleansed and ointment (Puralube) was applied to the eyes. An incision was made sagittally along the midline to expose the skull, the connective tissue and fascia were retracted, and lidocaine solution $(4 \mathrm{mg} / \mathrm{ml})$ was applied as a local anesthetic. A craniotomy with a diameter of $1.5 \mathrm{~mm}$ was made on the midline $1100 \mu \mathrm{m}$ caudal of Lambda using a small dental drill bit. A Hamilton syringe filled with rAd Kv2.2DN $\left(1.25 \times 10^{12}\right.$ particles/ $\mathrm{ml})$ or Kv2.2WT $\left(1.1 \times 10^{12}\right.$ particles $\left./ \mathrm{ml}\right)$ was placed over the drill hole and lowered into the MNTB. Each animal received $2 \mu \mathrm{l}$ of rAd at a rate of $400 \mathrm{nl} / \mathrm{min}$ and the syringe was then slowly removed. Subsequently, the edges of the scalp were reconnected using a topical skin adhesive (Histoacryl) and anesthesia was stopped. Animals were removed from the stereotactic frame and recovered under surveillance before being placed back in their cages. Animals were killed for brain tissue collection 5-6 d later; the proportion and location of infected cells within the MNTB varied over a diameter of $\sim 100 \mu \mathrm{m}$ and transfected neurons were recognized for in vitro recording using the EGFP fluorescence.

Auditory brainstem recordings. Mice (P20-P30) were anesthetized by intraperitoneal injection with a combination of fentanyl $(0.15 \mathrm{mg} / \mathrm{kg})$, fluanisone $(5 \mathrm{mg} / \mathrm{kg})$, and Hypnovel $(2.5 \mathrm{mg} / \mathrm{kg})$. Auditory brainstem recording (ABR) responses were evoked by tone pips (8/12/16/24/30 $\mathrm{kHz}, 1 \mathrm{~ms}$ rise and fall times, $5 \mathrm{~ms}$ duration, $3 \mathrm{~ms}$ plateau) and clicks (broadband between 2 and $20 \mathrm{kHz}, 100 \mu \mathrm{s}$ ) generated by a Thurlby Thandar arbitrary waveform generator (TGA 1230, $300 \mathrm{MHz}$ ) and unilaterally applied at $10 \mathrm{~Hz}$ using a Brüel and Kjaer model \#4192 microphone placed $\sim 2 \mathrm{~mm}$ above the ear. The final ABR response constituted an average of 100-400 individual traces recorded by intradermal electrodes (positive, negative, and ground electrodes were inserted subcutaneously at the vertex, mastoid, and back, respectively) with an input gain of $20 \mu \mathrm{V} / \mathrm{div}$ connected to an amplifier (Medelec Sapphire 2A; Oxford Instruments) and sampled at rate of $16 \mathrm{kHz}$. Hearing thresholds were determined by reducing the initial stimulus intensity (calibrated and provided in $\mathrm{dB}$ SPL) by 10 or $3 \mathrm{~dB}$ SPL (Tucker Davis Technology) steps until the ABR wave I and II could no longer be defined.

$A O E$. For AOE, mice were anesthetized as described for the ABR procedure and placed in a home-made sound-insulated box containing a loudspeaker (WF09K, frequency range $4-40 \mathrm{kHz}$; ProSound). A pure tone $(14.8 \mathrm{kHz})$ at $110 \mathrm{~dB}$ SPL was delivered for $30 \mathrm{~min}$. Anesthesia was used during the AOE for ethical reasons. Although anesthesia may reduce the MOC reflex (Lima da Costa et al., 1997; Guitton et al., 2004; Chambers et al., 2012), fentanyl does not reduce the MOC reflex in other rodents (Boyev et al., 2002). Furthermore, from the experimental viewpoint, both control mice and test $\mathrm{Kv} 2.2 \mathrm{KO}$ mice received identical anesthesia in the studies conducted here. Both WT and Kv2.2KO mice showed an initial temporary raised ABR threshold after AOE, whereas a residual threshold shift persisted for several weeks. Both "temporary" and "permanent" threshold shifts are mitigated by MOC stimulation 
(Handrock and Zeisberg, 1982; Rajan, 2000) and exacerbated by MOC deactivation (Liberman and Gao, 1995; Rajan, 2001). In this study, we concentrated on the longer-term elevation in auditory thresholds by studying the changes after a recovery period of $7 \mathrm{~d}$.

Immunohistochemistry. Brainstems were removed from $\mathrm{P} 13-\mathrm{P} 16$ $\mathrm{Kv} 2.2 \mathrm{WT} / \mathrm{Kv} 2.2 \mathrm{KO}$ mice) and frozen in LAMB OCT compound (Thermo Fisher Scientific). Cryostat sections in the transverse plane were cut (Microm HM 560; Thermo Fisher Scientific) at a thickness of $12 \mu \mathrm{m}$ and mounted on prepared slides, followed by fixation with $4 \%$ PFA/PBS for $25 \mathrm{~min}$ at $4^{\circ} \mathrm{C}$. After washing in $100 \mathrm{~mm}$ PBS with $0.1 \%$ Triton X-100 (PBS-T), antigen retrieval was performed in $10 \mathrm{~mm}$ citrate buffer ( $\mathrm{pH} 6$ ) at $95^{\circ} \mathrm{C}$ for $20 \mathrm{~min}$, followed by rewashing in PBS-T. Sections were then incubated for $30 \mathrm{~min}$ at room temperature with blocking buffer (PBS-T with $1 \%$ bovine serum albumin and $1 \%$ goat serum) to reduce nonspecific antibody binding. The primary antibodies anti-Kv2.2 (1:1000; Alomone) and anti-Kv3.1b (1:1000; NeuroMab) were applied to sections in the same buffer overnight at $4^{\circ} \mathrm{C}$. After washing $3 \times 15$ min with PBS-T, sections were incubated with the following secondary antibodies for $2 \mathrm{~h}$ at room temperature: goat anti-rabbit IgG Alexa Fluor 546 (red) or Alexa Fluor 488 (green) and goat anti-mouse Alexa Fluor 488 (1:1000; Invitrogen). After washing in PBS-T, sections were mounted with Vectashield Hard-Set Mounting Medium containing DAPI (Vector Laboratories).

Cochlea immunohistochemistry was conducted using a modified protocol (requiring decalcification), so antibody specificity was determined by conducting cochlea staining in parallel with brainstem tissue as a positive control for Kv2.2 immunostaining. Kv2.2KO (P15) and CBA (P15-P17) mice were anesthetized with $3 \mu \mathrm{l} / \mathrm{g}$ of body weight of $0.25 \mu \mathrm{l}$ Hypnorm, $0.25 \mu \mathrm{l}$ Midazolam, $0.5 \mu \mathrm{l}$ water and the vascular system was flushed with cold $\left(0^{\circ} \mathrm{C}\right)$ physiological saline and then perfused with a PBS saline containing 4\% PFA for 15-20 min. Cochleae and brainstem were carefully dissected and placed in $8 \%$ EDTA (for decalcification) overnight at $4^{\circ} \mathrm{C}$. Tissue was cryoprotected in $30 \%$ sucrose for $8 \mathrm{~h}$ and then left overnight in OCT/LAMB embedding matrix to allow infiltration. Tissue was frozen using dry-ice-cooled hexane and stored at $-80^{\circ} \mathrm{C}$ until required. Cryostat sections were cut (12 $\mu \mathrm{m}$ thick; Microm HM 560), washed in $1 \times$ PBS-T, and antigen retrieval (10 mM citrate buffer, $\mathrm{pH} 6$, $20 \mathrm{~min}, 95^{\circ} \mathrm{C}$ ) was performed, followed by washing in PBS-T. Sections were incubated for $60 \mathrm{~min}$ with blocking buffer (PBS-T with 1\% bovine serum albumin, $1 \%$ goat serum) at room temperature to reduce nonspecific binding. The primary antibodies anti-Kv2.1 and anti-Kv2.2 were applied to cochlea sections and incubated overnight at $4^{\circ} \mathrm{C}$. Staining with secondary antibodies was as stated above for the brainstem, substituting goat anti-rabbit Alexa Fluor 488 (green) and/or goat anti-mouse Alexa Fluor 546 (red), respectively. These tissue sections showed no specific staining for Kv2.2 in the cochlea hair cells or spiral ganglia, but specific staining for Kv2.2 was observed in the MNTB and VNTB of brainstem sections treated in an identical manner and in parallel.

Forty-eight hours after infection with Kv2.2WT/DN rAd, Neuro-2a cells were fixed on coverslips with $4 \%$ PFA for $10 \mathrm{~min}$ at room temperature. After washing in PBS, cells were permeabilized in $0.2 \%$ Triton $\mathrm{X}-100$ containing PBS for $15 \mathrm{~min}$ and then incubated in the blocking buffer for $20 \mathrm{~min}$, followed by $1 \mathrm{~h}$ of incubation in the primary anti-Kv2.2 antibody at room temperature. After washing, the secondary antibody (goat anti-rabbit IgG Alexa Fluor 546) was applied to cells for $1 \mathrm{~h}$ at room temperature. The coverslips were then mounted with Vectashield Hard Set Mounting Medium with DAPI (Vector Laboratories). Control cells with no rAd infection went through the same procedure and showed no specific staining.

Images were obtained using a Zeiss LSM 510 confocal microscope or a Leica DM2500 fluorescence microscope. For rAd-infected animals, transverse slices $(200 \mu \mathrm{m})$ containing EGFP-labeled MNTB and VNTB were imaged in the brain slice and fixed with 4\% PFA for $2 \mathrm{~h}$. After washing, images of EGFP-labeled neurons were obtained using multiphoton excitation from a near IR pulsing laser tuned to $780 \mathrm{~nm}$ (Mai Tai DeepSee-Spectra Physics; Newport).

MOC neuron retrograde labeling was conducted in vitro using P16 CBA mice $(n=4)$ killed by decapitation. The pinna, tympanic membrane, and ossicles were removed. A small hole was made in the cochlear wall between the basal and second turn. Approximately $0.5 \mu l$ of dextran- tetramethyl-rhodamine (MW 3000, 5\% dissolved in PBS; Invitrogen) was introduced into the scala vestibuli by pressure ejection from a glass micropipette (borosilicate glass capillaries, GC150F-7.5; Harvard Apparatus). The hole was widened if necessary to allow a bipolar tungsten electrode to be inserted into the cochlea. Electroporation was performed using a BTX ECM 830 (Haustein et al., 2010; protocol: $1 \times 120 \mathrm{~V}$ pulse for $130 \mathrm{~ms}$, then $60 \times 50 \mathrm{~ms} 50 \mathrm{~V}$ ) before repositioning the electrode and repeating the protocol for a second time. The top of the skull, including that overlying the dorsal surface of the brainstem and the cerebrum, were removed. The bone overlying the contralateral brainstem was also removed to allow greater perfusion with aCSF without disrupting the ipsilateral auditory nerve. The tissue was left in oxygenated aCSF at room temperature and agitated on a rocker table for $2-3 \mathrm{~h}$. After this time, the brainstem was dissected free from the remaining bone and placed in OCT/LAMB embedding medium and frozen in liquid hexane. Tissue was stored overnight at $-20^{\circ} \mathrm{C}$ before sectioning $\left(12 \mu \mathrm{m}\right.$ at $\left.-15^{\circ} \mathrm{C}\right)$. Tissue was fixed in 4\% PFA and stained for Kv2.2 immunoreactivity as described above but using a goat anti-rabbit Alexa Fluor 488 secondary antibody (green) and imaged using a Leica DM2500 light microscope and CCD camera (DFC 350 FX).

Statistics. Data are presented as the mean \pm SEM and were analyzed using Student's $t$ test (paired or unpaired as indicated). $p<0.05$ was considered statistically significant.

\section{Results}

\section{Kv2.2 in MNTB and VNTB neurons enables sustained firing during repetitive stimulation}

Kv2.2 subunits are highly expressed in the MNTB and VNTB (Fig. 1a). In the MNTB, Kv2.2 labeling is predominantly localized to the axon initial segment (Fig. $1 b$; Johnston et al., 2008) and is tonotopically distributed, being highest toward the medial (highfrequency) end of the nucleus. In the VNTB, Kv2.2 labeling is apparent in the plasma membrane, cytoplasm, and proximal dendritic tree (Fig. 1c). Kv2.2KO mice showed no labeling with Kv2.2 antibodies (Fig. 1d). In general, MNTB cells have large, round cell bodies with few dendrites, a compact morphology that allows good space-clamp for voltage-clamp studies. VNTB cells are smaller but with more dendrites and thus have properties less conducive to good space-clamp. We have combined studies of both MNTB and VNTB cells to examine the physiological role of Kv2.2 channels on a cellular and systems level, respectively.

To avoid the consequences of rapid rundown of potassium currents in the absence of auditory activity and intrinsic signaling after killing of the animal, whole-cell patch-clamp recordings were made from MNTB neurons within minutes of death (Steinert et al., 2011). These recordings revealed large outward $\mathrm{K}^{+}$ currents that were predominantly mediated by Kv2.2 containing channels because such large currents were absent in the Kv2.2KO mice (Fig. 2a). The mean I/V relationship revealed $41.31 \pm 4.43$ $\mathrm{nA}$ at $+29 \mathrm{mV}(n=4)$ of outward current in the WT and was reduced to about half the size $(21.86 \pm 1.94 \mathrm{nA}, n=7, p=0.005)$ in $\mathrm{Kv} 2.2 \mathrm{KO}$ mice (Fig. $2 b$ ). Using direct stimulation of the postsynaptic neuron with repetitive current pulses over the course of $1 \mathrm{~s}$, MNTB neurons responded reliably to every stimulus up to $400 \mathrm{~Hz}$ (Fig. 2c). The average entrainment even at $1000 \mathrm{~Hz}$ and after $1000 \mathrm{~ms}$ did not drop $<80 \%$ (Fig. 2 d). In the Kv2.2KO mice, however, MNTB neurons were unable to follow high-frequency trains of stimuli. VNTB neurons also showed large outward $\mathrm{K}^{+}$ currents $(18.90 \pm 1.25 \mathrm{nA}, n=10)$, which were significantly reduced in $\mathrm{Kv} 2.2 \mathrm{KO}$ mice $(7.13 \pm 1.18 \mathrm{nA}$ at $+39 \mathrm{mV}, n=6, p \leq$ 0.001 , Fig. $2 e, f)$. In response to repetitive stimulation, even a 100 $\mathrm{Hz}$ train caused VNTB neurons of Kv2.2KO mice to fail by $>50 \%$ (Fig. 2g,h). 

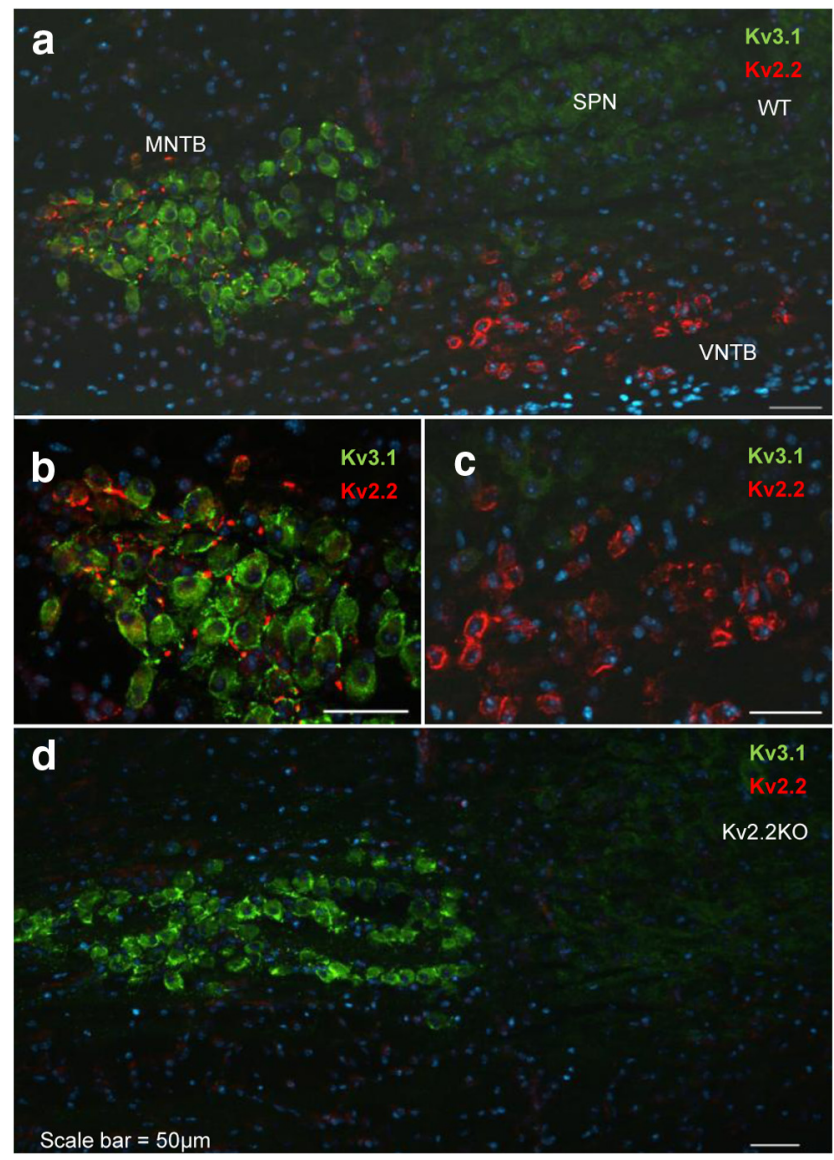

Figure 1. Kv2.2 is exclusively expressed in the MNTB and VNTB nuclei of the SOC. $\boldsymbol{a}$, Coimmunostaining of the MNTB, VNTB, and the superior paraolivary nucleus (SPN) with antibodies to Kv3.1b (green) and Kv2.2 (red); nuclei are stained with DAPI (blue). MNTB principal neurons also show intense labeling for Kv3.1b (green), whereas the VNTB exhibits only Kv2.2 staining. $\boldsymbol{b}$, Kv2.2 is present in MNTB neurons, but is restricted to the axon initial segment and is particularly intense in the medial part of the nucleus. $c$, The smaller VNTB cells show somatic staining for Kv2.2.d, Tissue from a Kv2.2KO mouse shows similar Kv3.1 labeling in the MNTB but no labeling with Kv2.2 antibodies in either MNTB or VNTB. Scale bars, $50 \mu \mathrm{m}$. Top is dorsal and left is medial.

\section{Control experiments confirm that $\mathrm{Kv} 2.2$ is not expressed in} the cochlea

There is clear evidence for Kv2.2 expression in the auditory brainstem, but we also tested the possibility that Kv2.2 might be expressed in the cochleae. Because of the additional decalcification step in the cochlea immunohistochemistry method, we first confirmed that the Kv2.2Ab was specific under these experimental conditions by demonstrating Kv2.2Ab staining in the VNTB of WT mice (Fig. $3 a$ ) in slices that were treated identically to the sections obtained from the cochlea. This clearly shows specific Kv2.2 staining the WT VNTB, which was absent in tissue from the Kv2.2KO mouse (Fig. 3b). Cochlear sections from WT and $\mathrm{Kv} 2.2 \mathrm{KO}$ animals were treated with an identical protocol and then Kv2.2 and Kv2.1 immunohistochemistry was performed. Kv2.1 immunoreactivity was observed, consistent with previous results (Li et al., 2012), but no specific Kv2.2 staining (Fig. 3c,d) was observed in the hair cells or in the spiral ganglion (data not shown). In conjunction with the positive control from the brainstem, we conclude that there is no Kv2.2 expressed in the cochlea and thus any changes in hearing associated with the absence of Kv2.2 must reflect a central rather than a peripheral location of this channel. a
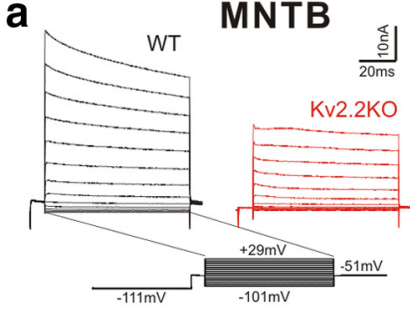

C

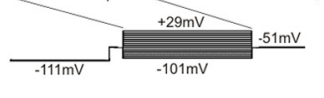

WT $(400 \mathrm{~Hz})$
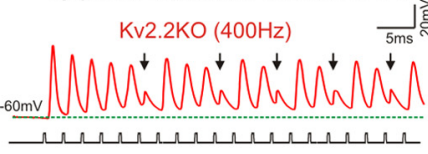

e

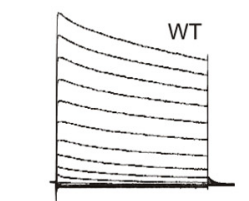

g

VNTB
MNTB

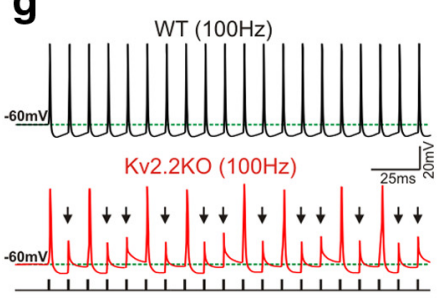

b

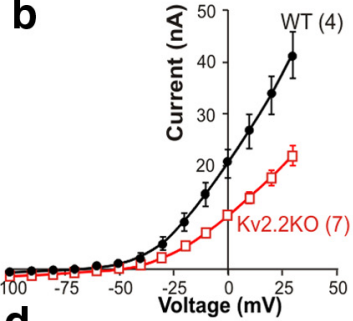

d
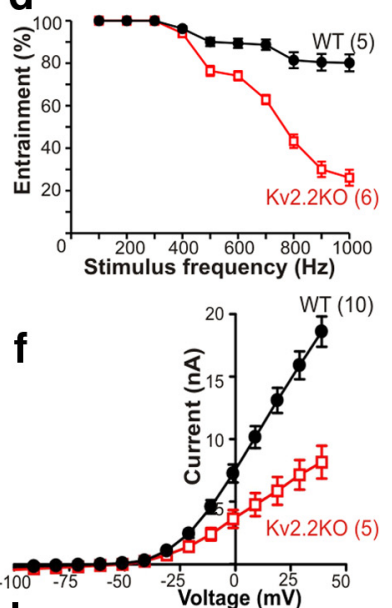

h

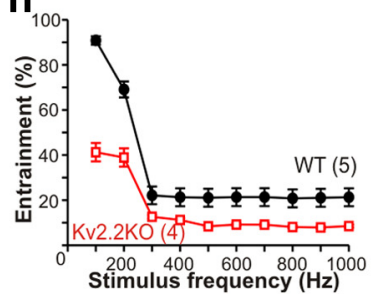

Figure 2. Kv2.2 enables high-frequency firing. $\boldsymbol{a}, 0$ utward $\mathrm{K}^{+}$currents from WT-MNTB neurons (black) are much larger than those from a Kv2.2K0 mouse (red). Recordings were made within $20 \mathrm{~min}$ of the killing of the animal. Voltage protocol is shown below. $\boldsymbol{b}, \mathrm{I} / \mathrm{V}$ relationship for average $\mathrm{K}^{+}$currents measured in the MNTB show large magnitude currents WT (black) compared with the smaller currents from the Kv2.2KO (red). c, In current-clamp, a $400 \mathrm{~Hz}$ train of short depolarizing stimuli reliably induced APs in response to every stimulus repetition in WT-MNTB, whereas neurons from the Kv2.2K0 exhibited failures (arrows). $\boldsymbol{d}$, On average, WT MNTB neurons reliably followed stimulus trains up to $1000 \mathrm{~Hz}$, with entrainment never dropping below $80 \%$. Entrainment in Kv2.2KO neurons dropped significantly for stimulation frequencies of $400 \mathrm{~Hz}$ or above. $e$, Outward $\mathrm{K}^{+}$currents in WT-VNTB neurons (black) were large and slightly inactivating, whereas $\mathrm{K}^{+}$currents in Kv2.2KO VNTB neurons were strongly inactivating (reflecting the absence of slowly activating Kv2.2 currents (KO, red). $f$, Steady-state I/Vs were significantly different for VNTB neurons between genotypes. $\boldsymbol{g}$, VNTB neurons are less able to follow high-frequency stimulus trains even in WT mice (black), but Kv2.2KO VNTB neurons cannot even follow a $100 \mathrm{~Hz}$ stimulus train without skipping cycles (red). $\boldsymbol{h}$, The average ability to follow stimulation in VNTB neurons during repetitive stimulation shows high transmission at frequencies up to $200 \mathrm{~Hz}$ in the WT, but responses only to every other cycle in the Kv2.2KO.

\section{Kv2.2 currents are suppressed or restored by respective} transfection with Kv2.2DN or Kv2.2WT subunits

The absence of specific pharmacological blockers for Kv2 channels makes it difficult to study these native currents (Johnston et al., 2008). Furthermore, compensation or developmental adaptations could confound the interpretation of data from the knock-out animals. Therefore, we used viral vector gene delivery methods using a second generation rAd vector (see Materials and Methods) to express a DN Kv2.2 channel to suppress Kv2.2 currents and to complement the above methods in normally developed (posthearing) WT mice. The efficacy of both rAd vectors, 

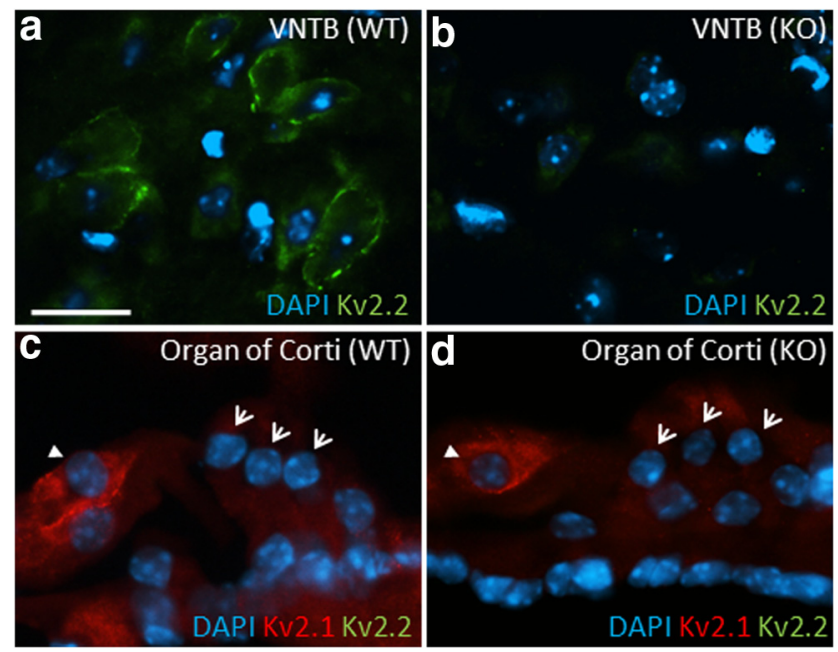

Figure 3. Kv2.2 is not expressed in the cochlea. $\boldsymbol{a}, \boldsymbol{b}, \mathrm{WT}(\boldsymbol{a})$ and Kv2.2KO (b) brainstem sections (transverse plane) served as positive and negative controls, respectively, confirming that the Kv2.2 antibody is specific under the modified protocol required for cochlea sectioning and immunohistochemistry. c, Immunostaining of organ of Corti cross-sections in the cochlea from WT mice showed Kv2.1 staining, but no specific Kv2.2 immunoreactivity was observed. $\boldsymbol{d}$, Identical staining was observed in the Kv2.2KO tissue. Open arrows indicate $\mathrm{OHCs}$; filled arrow, IHCs. Representative images from WT $(n=3)$ and KO $(n=3)$ are shown. Scale bar, 20 $\mu \mathrm{m}$.

encoding Kv2.2WT and Kv2.2DN, was first tested in a neuro2A cell line (Fig. 4a), which showed large Kv2.2 currents when transfected with Kv2.2WT; however, no currents were evoked in nontransfected control cells or when transfected with the Kv2.2DN virus (Fig. 4b). Activation rates of the Kv2.2WT currents were fit by a single exponential and proved to be highly voltage dependent, showing an e-fold acceleration with $18.4 \mathrm{mV}$ depolarization $(n=11)$ at room temperature. Faster activation rates were observed at $32^{\circ} \mathrm{C}$. Activation and inactivation curves for the Kv2.2WT currents were fit by Boltzmann functions (Fig. 4c). Half-activation $(-9.5 \mathrm{mV})$ and half-inactivation $(-38.8 \mathrm{mV})$ mirrored the values described previously (Johnston et al., 2008) and confirmed the quality of the viral transfection. We used these vectors to suppress Kv2.2 expression in MNTB of WT mice and to restore Kv2.2 function in Kv2.2 knock-out mice. Independent coexpression of EGFP from the rAd Kv2.2 vectors allowed visualization of the transfected neurons that expressed the Kv2.2WT or Kv2.2DN (Fig. 4a,d, inset). Whole-cell patch-clamp recordings were made from neurons expressing EGFP. In the presence of tetraethylammonium (TEA, $1 \mathrm{~mm}$ ), which blocks highvoltage-activated Kv3 currents, current amplitudes of WT MNTB neurons were significantly reduced from $13.11 \pm 1.02 \mathrm{nA}$ $(n=4)$ to $6.76 \pm 1.55 \mathrm{nA}$ after expressing $\mathrm{Kv} 2.2 \mathrm{DN}(n=3 ; p=$ 0.016; Fig. 4d). Complementary "rescue" experiments were also conducted, in which viral expression of functional Kv2.2WT was performed in MNTB neurons from Kv2.2 knock-out mice to ensure that the reduction in the outward currents by Kv2.2DN expression was not due to a nonspecific effect of the virus infection. Kv2.2-mediated currents were restored in MNTB neurons of Kv2.2 knock-out mice from $16.21 \pm 1.85 \mathrm{nA}$ at $+39 \mathrm{mV}(n=$ $5)$ to amplitudes of $40.91 \pm 2.77 \mathrm{nA}(n=5$; Fig. $4 e)$. Again, TEA was used to exclude any contribution or compensation by Kv3 currents. The emerging Kv2.2-dominated current was similar in amplitude to the Kv2.2-dominated WT currents in the recordings shown in Fig. 2b. The slow kinetics of Kv2.2-mediated currents are highly characteristic (Johnston et al., 2008) and were not observed in neurons from the Kv2.2KO mice (Fig. $4 f$ ). Therefore, focal knock-down and rescue of Kv2.2 currents proved to be powerful tools in manipulating Kv2.2 channel function on a cellular level, and the results corroborate the use of the Kv2.2 knockout mice to assess system-level function.

\section{Kv2.2 facilitates AP repolarization and maintains repetitive firing}

The contribution of Kv2.2-mediated currents to AP firing was evaluated in current-clamp recordings from WT mice with Kv2.2 and mice lacking Kv2.2 expression (Kv2.2KO and Kv2.2DN). To understand how the AP shape is influenced by Kv2.2 currents, we compared the amplitudes and half-widths of APs between Kv2.2expressing and Kv2.2-lacking MNTB and VNTB neurons (Fig. $5 a, b)$. WT MNTB neurons typically have small, nonovershooting APs (to $-5.9 \pm 2.3 \mathrm{mV}, n=7$ ) with a half-width of $0.33 \pm 0.02 \mathrm{~ms}(n=13)$, whereas VNTB neurons exhibit larger AP overshoots (to $+12.8 \pm 4.8 \mathrm{mV}, n=5$ ) but slightly longer half-widths $(0.42 \pm 0.03 \mathrm{~ms}, n=5)$. The absence or downregulation of Kv2.2 currents caused a significant increase in AP halfwidth in both nuclei (MNTB-KO: $0.42 \pm 0.04 \mathrm{~ms}, n=12, p=$ 0.048; MNTB-DN: $0.56 \pm 0.01 \mathrm{~ms}, n=4, p \leq 0.001$; VNTB-KO: $0.58 \pm 0.05 \mathrm{~ms}, n=5$; VNTB-DN: $0.75 \pm 0.05 \mathrm{~ms}, n=8$ ). This change in AP half-width was followed by a change in firing pattern. MNTB neurons were generally characterized by a single AP response to depolarizing current steps (Fig. 5ci). Lack of Kv2.2 channels in knock-out mice or suppression of functional Kv2.2 channels in the Kv2.2DN transfected neurons changed the AP firing rate, with increased firing in proportion to the injected depolarizing current (Fig. 5cii). This increased excitability was accompanied by decreased AP thresholds in Kv2.2DN neurons from $200 \pm 13 \mathrm{pA}(n=7)$ to $130 \pm 34 \mathrm{pA}(n=5 ; p=0.047)$. The VNTB fired multiple APs during current injections $>50 \mathrm{pA}$ (Fig. 5 di), whereas larger current injections in Kv2.2KO VNTB mice caused the firing rate to drop significantly below their WT controls (Fig. 5dii). One explanation for this reduction in VNTB firing rate with high current injection is that the depolarization of the interspike potential (Fig. 5di) caused partial inactivation of sodium channels (Johnston et al., 2008). MNTB neurons have many other $\mathrm{Kv}$ conductances to aid repolarization and compensate for the lack of Kv2.2 and so are less susceptible to AP failure (Fig. 5ci). These data suggest that Kv2.2 function overlaps and complements Kv1 and of Kv3 and is of greater significance than was thought previously.

\section{Kv2.2 maintains VNTB excitability and MOC protection during AOE}

Having established the cellular function of Kv2.2 currents by patch-clamp recording, we now considered the broader physiological role of Kv2.2 in the firing behavior of VNTB neurons and the MOC system (Fig. 6a). We first confirmed that VNTB neurons that express Kv2.2 are part of the MOC system (Fujino et al., 1997) by in vitro injection of dextran-rhodamine into the cochlea. After incubation at room temperature for 2-3 h to allow time for retrograde transport, the tissue was processed for Kv2.2 immunohistochemistry. Neurons containing red fluorescence also expressed Kv2.2 immunostaining (green) as shown in the inset to Figure $6 a$. We could then ask: does the absence of VNTB Kv2.2 influence the efferent protection from AOE? As part of the MOC, VNTB function can be assessed by its protective role during an acoustic insult. Normal auditory function was tested by ABRs in response to different sound frequencies and intensities. In naive animals, no threshold differences were found between WT and 
Kv2.2KO mice (Fig. 6b), indicating that the absence of Kv2.2 has no impact on basal auditory thresholds. This is consistent with immunohistochemical evidence (validated using tissue from the $\mathrm{Kv} 2.2 \mathrm{KO}$ mouse) demonstrating that Kv2.2 was not expressed in the cochlea (Fig. 3). Multipeaked waveforms characteristic of WT ABRs evoked by click stimuli were similar in WT and Kv2.2KO mice (Fig. $6 c$, control). The protective function of the MOC was compared in WT and Kv2.2KO mice before and after they were subjected to AOE lasting $30 \mathrm{~min}$. Immediately after the acoustic insult, no ABRs were present in response to click stimuli in either genotype (data not shown). However, one week after the AOE, ABRs had largely recovered in WT mice, but not in $\mathrm{Kv} 2.2 \mathrm{KO}$ mice, with ABR thresholds being significantly elevated compared with WT controls (Fig. $6 d$ ). The reduced firing rate of VNTB neurons in the absence of Kv2.2 (Fig. 2g,h, Fig. 5d) demonstrates a decreased ability to sustain activity in the MOC efferent projection during and continuing beyond an acoustic insult. Such a tight feedback control between acoustic input and Kv2.2 activation is also suggested by the rapid decline of Kv2.2 currents after isolation of the brain from the auditory input (Steinert et al., 2011).

\section{Discussion}

Our results demonstrate a clear contribution of Kv2.2 potassium channels in regulating neuronal excitability and a specific role in hearing protection after an acoustic insult. Kv2.2 is expressed in two nuclei of the superior olivary complex (SOC): the MNTB and the VNTB. We have confirmed that Kv2.2 is not expressed in the cochlea and we have also demonstrated that the Kv2.2-expressing neurons of the VNTB do indeed project into the cochlea and are part of the MOC system. Therefore, the increase in sensitivity of a Kv2.2 knock-out mouse to noise exposure confirms a physiological role for this delayed rectifier potassium channel. Kv2 is activated by voltages intermediate to that activating Kv1 or Kv3 currents, so Kv2.2 can enhance or substitute for functional aspects of both of these $\mathrm{Kv}$ families in contributing to AP repolarization and neuronal excitability. During sustained loud sound exposure, VNTB/MOC neurons must maintain high firing rates to achieve protection from noise damage and, as we show here, this requires the expression of Kv2.2. This systems-level Kv2.2 function in the auditory brainstem
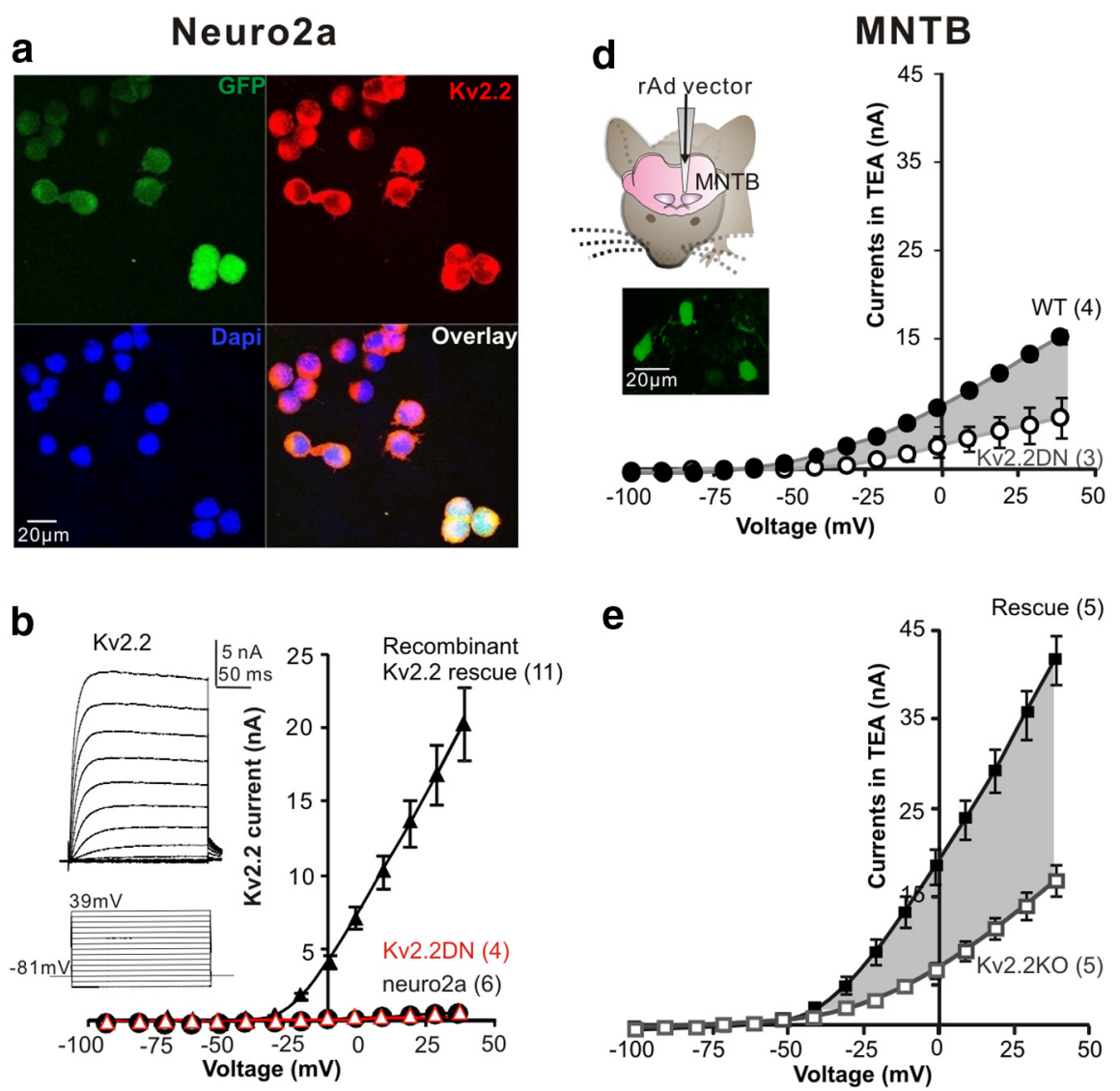

C

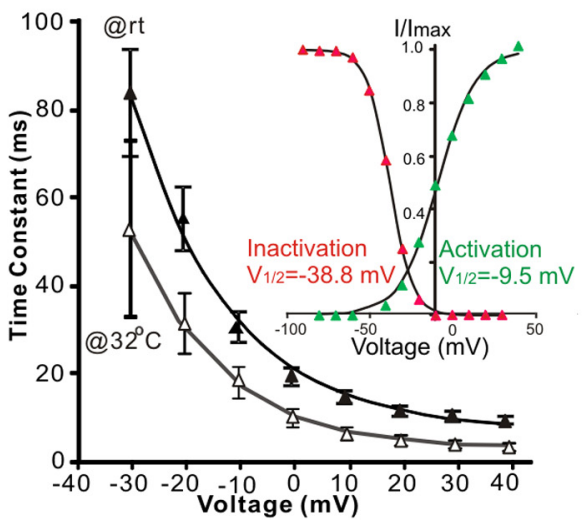

f

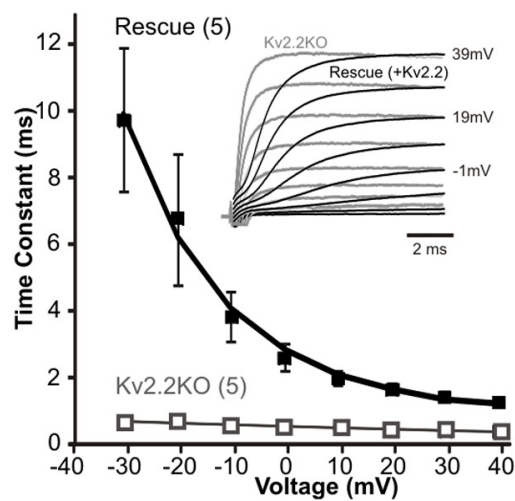

Figure 4. Suppression and rescue of Kv2.2 currents by respective transfection with viral vectors carrying Kv2.2DN or Kv2.2WT. $\boldsymbol{a}$, Confocal imaging shows neuro2a cells transfected with Kv2.2WT virus. Green EGFP of transfected cells are stained by a Kv2.2 antibody (red, Kv2.2); cell nuclei are indicated by DAPI (blue) and the overlay is shown (bottom right). $\boldsymbol{b}$, Whole-cell voltage-clamp shows large recombinant Kv2.2 currents from EGFP-positive cells after Kv2.2WT rAd infection (inset traces) with the mean I/V for 11 cells (black triangle). No currents were evoked in noninfected control cells (black circle) or when infected with the Kv2.2DN virus (open triangle).c, Recombinant Kv2.2WT activation rates were fit with a single exponential and are highly voltage dependent: the mean activation time constant is plotted against voltage and shows an e-fold acceleration with $18.4 \mathrm{mV}$ depolarization $(n=11)$ at room temperature (black triangle). Faster activation rates were observed at $32^{\circ} \mathrm{C}$ (gray open triangle, e-fold acceleration with $17.2 \mathrm{mV}$ depolarization, $n=9$ ). Inset shows activation (green) and inactivation (red) curves for the recombinant Kv2.2WT currents; fits to Boltzmann functions gave half-activation of $-9.5 \mathrm{mV}$ and half-inactivation was at $-38.8 \mathrm{mV}$. $\boldsymbol{d}, \mathrm{I} / \mathrm{V}$ relation for MNTB neurons in the presence of TEA ( $1 \mathrm{~mm}$, filled circle) and after Kv2.2DN rAd expression (open circle), shows clear suppression of native $\mathrm{K}^{+}$currents from injected animals. The inset shows a schematic of unilateral in vivo rAd vector injection to the mouse MNTB (top) and EGFP-positive MNTB neurons (bottom) from an injected mouse killed $4 \mathrm{~d}$ later. $\boldsymbol{e}$, TEA-insensitive $\mathrm{K}^{+}$currents are much greater in Kv2.2WT vector-injected Kv2.2K0 mice (Rescue, filled square) than those from control Kv2.2KO mice (open square). $f$, In the presence of TEA, MNTB neurons from rescued mice (filled square) exhibited classic Kv2.2 activation kinetics that were much slower than those from Kv2.2K0 mice (open square). The insert shows representative current traces from a rescued (black) and a Kv2.2KO (gray) MNTB neuron at indicated voltages. Both current traces were normalized to the same amplitude to highlight the slower activation of the Kv2.2 current. $n$ is indicated in brackets. 
MNTB

a

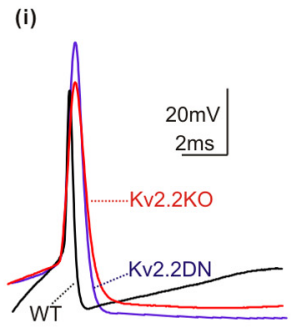

C

(i)

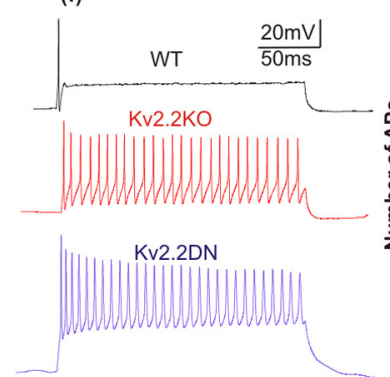

(ii)

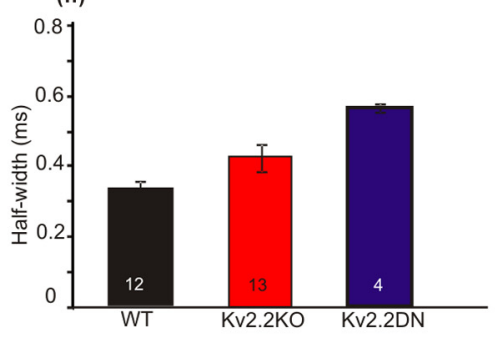

(ii) b

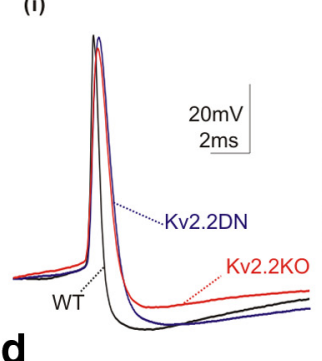

(i)

\section{VNTB}

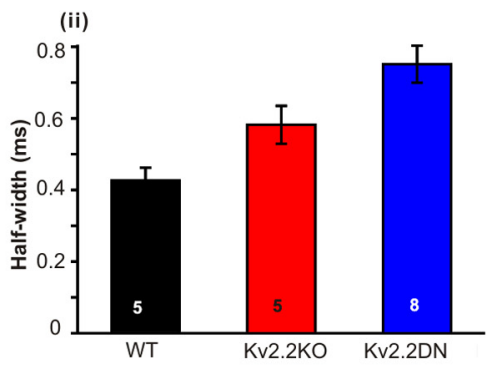

(ii)

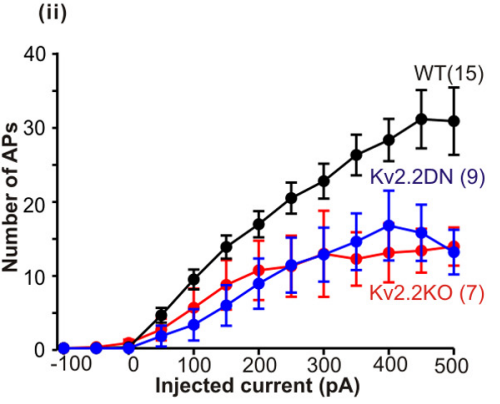

Figure 5. Kv2.2 channels are essential for maintaining AP firing patterns in both MNTB (left) and VNTB (right) neurons. $\boldsymbol{a}, \boldsymbol{b}$, Lack of functional Kv2.2 channels prolonged AP half-width in Kv2.2K0 (red) and Kv2.2DN (blue) compared with WT (black) for neurons from both MNTB (a) and VNTB (b). Bar graphs show average data for the change in AP half-width in the MNTB (aii) and in the VNTB (bii); $n$ values are given by the number in the bars. c, Example voltage traces (ci) in response to $400 \mathrm{pA}$ current injection, showed the characteristic single AP resonse in a WT MNTB neuron (black trace), but multiple APs were generated in Kv2.2KO mice (red trace) or after Kv2.2DN (blue trace). Neurons expressing Kv2.2DN or from Kv2.2K0 mice fired trains of APs in contrast to the single AP firing phenotype of WT. The average number of APs evoked during a $200 \mathrm{~ms}$ current step is plotted against the injected current magnitude (cii). $\boldsymbol{d}$, Example traces (di) show that VNTB AP firing is maintained throughout a step current injection (WT, black trace), whereas AP firing in the Kv2.2KO (red trace) and the Kv2.2DN (blue trace) fails to be maintained. The plot of mean AP firing (number of APs in $200 \mathrm{~ms}$, dii) against injected current shows that the Kv2.2KO and Kv2.2DN VNTB neurons cannot sustain firing during large depolarizations.

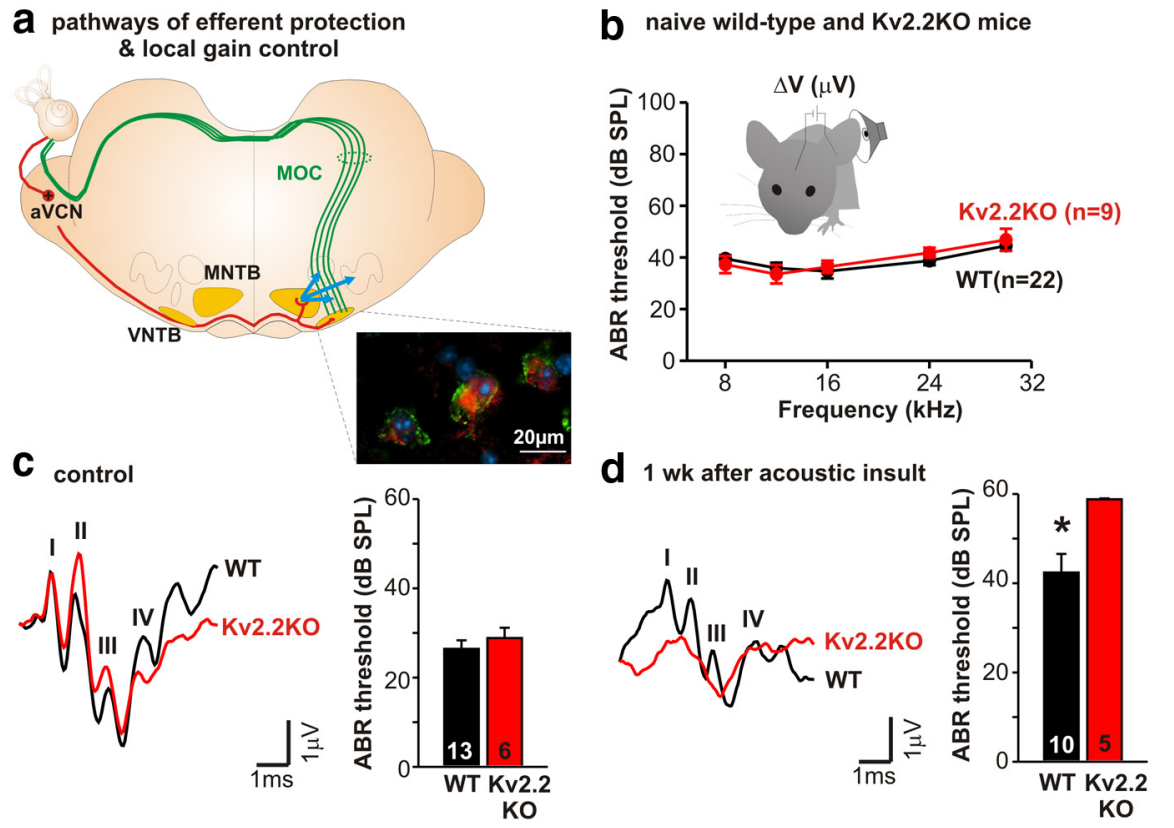

Figure 6. Kv2.2 channels in the MOC/VNTB neurons enhance protection from AOE. $\boldsymbol{a}$, Cross-section of the auditory brainstem shows afferent pathways (red) from the cochlea to the $\mathrm{SOC}$, via the ventral cochlear nucleus (VCN). The MNTB and VNTB are shown in yellow. The VNTB neurons provide part of the MOC efferent projection (green) to the cochlea; the MNTB gives an inhibitory projection (blue) to the other nuclei of the SOC. The inset image shows dextran-rhodamine (red)-labeled VNTB neurons, which were transported from the cochlea, and with the same cells also immunolabeled with Kv2.2 (green). $\boldsymbol{b}$, ABRs measured in vivo had similar thresholds in naive WT and Kv2.2KO mice across a frequency range of $8-30 \mathrm{kHz}$. c, Representative examples of ABRs measured in vivo in response to click stimulation. WT mice (black) and Kv2.2K0 (red) mice show up to four clearly distinguishable components in the ABR traces (labeled I-IV) and no genotype-specific difference in waveforms or threshold was observed. $\boldsymbol{d}$, Acoustic insult diminished all ABR components in the Kv2.2KO (red), indicating that the Kv2.2KO is much more sensitive to an acoustic insult, whereas WT animals (black) showed considerable recovery 1 week after the insult. Bar graph shows the significantly elevated mean ABR thresholds ( ${ }^{*} p<0.05$ ) in Kv2.2K0 mice 1 week after inducing an acoustic insult. suggests that these channels are an important component of the physiological mechanism protecting the cochlea from AOE.

Neurons of the VNTB are an integral part of the MOC efferent system (Fig. 6a) that regulates the $\mathrm{OHC}$ activity and the cochlear amplifier and thereby reduces the sound-evoked motion of the basilar membrane (Brown and Levine, 2008). This efferent feedback inhibition provides an efficient mechanism to protect the sense organ from sound damage (Cooper and Guinan, 2006; Ashmore, 2008; Wersinger and Fuchs, 2011), with in vivo protection being maximized by repetitive activation of the efferents, leading to facilitation and summation of transmitter release onto OHCs (Ballestero et al., 2011). Monaural or binaural acoustic stimulation of the MOC in vivo evoked maximum firing rates of $80-140 \mathrm{~Hz}$ (Liberman, 1988). Here we demonstrate that high expression of Kv2.2 potassium channels sustains efferent MOC firing to frequencies of $200 \mathrm{~Hz}$. Although the MNTB and VNTB both express high levels of Kv2.2, their upper firing rates differ, reflecting differing expression of other ion channels (and the location of these channels) in controlling the overall intrinsic excitability. 
There are two injuries associated with AOE: a temporary threshold shift that is most prominent in the first $24 \mathrm{~h}$ and a residual threshold shift that persists for weeks and could reflect loss of hair cells and is considered "permanent." Several studies have shown that activation of the MOC system with either electrical stimulation of the olivocochlear tract or acoustic stimulation can reduce both threshold shifts after AOE (Handrock and Zeisberg, 1982; Rajan, 1988, 2000, Rajan and Johnstone, 1988) and cochlear neuropathy (Maison et al., 2013) even after moderate noise exposure. Conversely, deactivation of the MOC system exacerbates the damage caused by loud sound (Liberman and Gao, 1995; Rajan, 2001). These studies support the hypothesis that the MOC system acts to protect the ear from damage during intense noise exposure. Reduced firing of the MOC/VNTB would translate into reduced feedback inhibition necessary to protect $\mathrm{OHCs}$ from sound damage. Consistent with this idea, the findings from $\mathrm{Kv} 2.2 \mathrm{KO}$ mice indicate greater vulnerability to acoustic injury, demonstrating that Kv2.2 channels expressed in the VNTB neurons contribute to protection from AOE.

The Kv2 potassium channel family has two members: Kv2.1 and Kv2.2. The former is highly expressed in the hippocampus and neocortex (Du et al., 2000; Guan et al., 2007) and hair cells (Li et al., 2012), where Kv2.1-containing channels are considered the dominant delayed rectifiers and are responsible for AP repolarization. Kv2.2 has a much more restricted expression profile and in the auditory brainstem is expressed exclusively in the initial segment of the MNTB neurons and in VNTB neurons. Immunohistochemistry of the cochlea showed no specific Kv2.2 staining (using identical antibodies and conditions to our positive controls in the brainstem neurons). This result shows that the enhanced sensitivity to loud sounds in the Kv2.2 knock-out must be the consequence of lacking central rather than peripheral Kv2.2. Our studies also show that the ABRs from the Kv2.2KO mouse under control conditions are identical to those of WT animals, so the possibility of developmental differences in this constitutive knock-out strain seems unlikely.

The basic role of Kv2.2 is as a delayed rectifier that is similar in both the MNTB and VNTB in terms of accelerating AP repolarization (generating shorter duration APs) and controlling neuronal excitability. Kv2.2 potassium channels are slowly activating and deactivating channels that hyperpolarize the membrane potential between APs during high-frequency firing. This reduces refractory periods and promotes recovery of $\mathrm{Na}^{+}$currents from inactivation (Johnston et al., 2008). The modest firing rates of VNTB neurons compared with MNTB neurons are not surprising. From a physiological perspective, they are consistent with the longer time course of nicotinic IPSCs, which decay with a time constant of 25-50 ms (Gómez-Casati et al., 2005; Ballestero et al., 2011), and thus in the cochlea will summate with firing rates well $<200 \mathrm{~Hz}$. This contrasts with the MNTB, in which AMPAR EPSCs decay with kinetics faster than $1 \mathrm{~ms}$ and therefore summate (Postlethwaite et al., 2007) only at much higher firing frequencies $(>200 \mathrm{~Hz})$.

There are multiple levels of feedback control from the SOC to the cochlea. First, there is the direct activity of the MOC to the $\mathrm{OHCs}$ controlling the cochlear amplifier. Second, the primary afferent excitability from the IHCs is regulated by the lateral olivocochlear system. Third, reduced olivocochlear feedback will enhance synaptic strength of excitatory projections to the MNTB, thereby potentiating the inhibitory drive to the other nuclei of the SOC because the MNTB output is an inverting relay. Therefore, enhanced excitatory responses to sound will provide enhanced
MNTB-mediated inhibition, which in turn suppresses the target nuclei within the SOC (Johnston et al., 2010).

So how can sound activity regulate Kv2.2 currents? Recent evidence suggests that glutamatergic synaptic activity modulates Kv2.2 currents via nitric oxide signaling. Neuronal nitric oxide synthase is present in the SOC, including the VNTB, and is particularly highly expressed in the MNTB (Fessenden et al., 1999; Schaeffer et al., 2003; Steinert et al., 2008). Recently, we have shown that the NO/cGMP signaling pathway enhances Kv2 currents in a synaptic-activity-dependent manner (Steinert et al., 2011).

The limited expression of Kv2.2 subunits in the MNTB and VNTB of the SOC has provided insights into the general role of Kv2.2 in maintaining AP firing in the MNTB (Johnston et al., 2008) and for maintaining high-frequency firing in the efferent pathway, as shown here in the VNTB. Our studies demonstrate a clear role for activity-driven modulation of Kv2.2 currents (Kopp-Scheinpflug et al., 2011; Steinert et al., 2011) that enables effective efferent protection of the cochlea from damaging levels of sound exposure.

\section{References}

Ashmore J (2008) Cochlear outer hair cell motility. Physiol Rev 88:173-210. CrossRef Medline

Ballestero J, Zorrilla de San Martín J, Goutman J, Elgoyhen AB, Fuchs PA, Katz E (2011) Short-term synaptic plasticity regulates the level of olivocochlear inhibition to auditory hair cells. J Neurosci 31:14763-14774. CrossRef Medline

Barnes-Davies M, Forsythe ID (1995) Pre- and postsynaptic glutamate receptors at a giant excitatory synapse in rat auditory brainstem slices. J Physiol 488:387-406. Medline

Boyev KP, Liberman MC, Brown MC (2002) Effects of anesthesia on efferent-mediated adaptation of the DPOAE. J Assoc Res Otolaryngol 3:362-373. CrossRef Medline

Brew HM, Forsythe ID (1995) Two voltage-dependent $\mathrm{K}^{+}$conductances with complementary functions in postsynaptic integration at a central auditory synapse. J Neurosci 15:8011-8022. Medline

Brown MC, Levine JL (2008) Dendrites of medial olivocochlear neurons in mouse. Neuroscience 154:147-159. CrossRef Medline

Brown MC, Nuttall AL (1984) Efferent control of cochlear inner hair cell responses in the guinea-pig. J Physiol 354:625-646. Medline

Chambers AR, Hancock KE, Maison SF, Liberman MC, Polley DB (2012) Sound-evoked olivocochlear activation in unanesthetized mice. J Assoc Res Otolaryngol 13:209-217. CrossRef Medline

Coetzee WA, Amarillo Y, Chiu J, Chow A, Lau D, McCormack T, Moreno H, Nadal MS, Ozaita A, Pountney D, Saganich M, Vega-Saenz de Miera E, Rudy B (1999) Molecular diversity of $\mathrm{K}^{+}$channels. Ann N Y Acad Sci 868:233-285. CrossRef Medline

Cooper NP, Guinan JJ Jr (2006) Efferent-mediated control of basilar membrane motion. J Physiol 576:49-54. CrossRef Medline

Du J, Haak LL, Phillips-Tansey E, Russell JT, McBain CJ (2000) Frequencydependent regulation of rat hippocampal somato-dendritic excitability by the $\mathrm{K}^{+}$channel subunit Kv2.1. J Physiol 522:19-31. CrossRef Medline Elgoyhen AB, Johnson DS, Boulter J, Vetter DE, Heinemann S (1994) Alpha 9: an acetylcholine receptor with novel pharmacological properties expressed in rat cochlear hair cells. Cell 79:705-715. CrossRef Medline

Eyre MD, Kerti K, Nusser Z (2009) Molecular diversity of deep short-axon cells of the rat main olfactory bulb. Eur J Neurosci 29:1397-1407. CrossRef Medline

Fessenden JD, Altschuler RA, Seasholtz AF, Schacht J (1999) Nitric oxide/ cyclic guanosine monophosphate pathway in the peripheral and central auditory system of the rat. J Comp Neurol 404:52-63. CrossRef Medline

Fujino K, Koyano K, Ohmori H (1997) Lateral and medial olivocochlear neurons have distinct electrophysiological properties in the rat brain slice. J Neurophysiol 77:2788-2804. Medline

Garcia-Guzman M, Calvo S, Ceña V, Criado M (1992) Molecular cloning and permanent expression in a neuroblastoma cell line of a fast inactivating potassium channel from bovine adrenal medulla. FEBS Lett 308:283289. CrossRef Medline 
Gómez-Casati ME, Fuchs PA, Elgoyhen AB, Katz E (2005) Biophysical and pharmacological characterization of nicotinic cholinergic receptors in rat cochlear inner hair cells. J Physiol 566:103-118. CrossRef Medline

Guan D, Tkatch T, Surmeier DJ, Armstrong WE, Foehring RC (2007) Kv2 subunits underlie slowly inactivating potassium current in rat neocortical pyramidal neurons. J Physiol 581:941-960. CrossRef Medline

Guitton MJ, Avan P, Puel JL, Bonfils P (2004) Medial olivocochlear efferent activity in awake guinea pigs. Neuroreport 15:1379-1382. CrossRef Medline

Handrock M, Zeisberg J (1982) The influence of the efferent system on adaptation, temporary and permanent threshold shift. Arch Otorhinolaryngol 234:191-195. CrossRef Medline

Haustein MD, Read DJ, Steinert JR, Pilati N, Dinsdale D, Forsythe ID (2010) Acute hyperbilirubinaemia induces presynaptic neurodegeneration at a central glutamatergic synapse. J Physiol 588:4683-4693. CrossRef Medline

Hermanstyne TO, Kihira Y, Misono K, Deitchler A, Yanagawa Y, Misonou H (2010) Immunolocalization of the voltage-gated potassium channel Kv2.2 in GABAergic neurons in the basal forebrain of rats and mice. J Comp Neurol 518:4298-4310. CrossRef Medline

Johnston J, Griffin SJ, Baker C, Skrzypiec A, Chernova T, Forsythe ID (2008) Initial segment Kv2.2 channels mediate a slow delayed rectifier and maintain high frequency action potential firing in medial nucleus of the trapezoid body neurons. J Physiol 586:3493-3509. CrossRef Medline

Johnston J, Forsythe ID, Kopp-Scheinpflug C (2010) Going native: voltagegated potassium channels controlling neuronal excitability. J Physiol 588: 3187-3200. CrossRef Medline

Kaczmarek LK, Bhattacharjee A, Desai R, Gan L, Song P, von Hehn CA, Whim MD, Yang B (2005) Regulation of the timing of MNTB neurons by short-term and long-term modulation of potassium channels. Hear Res 206:133-145. CrossRef Medline

Karcz A, Hennig MH, Robbins CA, Tempel BL, Rübsamen R, KoppScheinpflug C (2011) Low-voltage activated Kv1.1 subunits are crucial for the processing of sound source location in the lateral superior olive in mice. J Physiol 589:1143-1157. CrossRef Medline

Kihira Y, Hermanstyne TO, Misonou H (2010) Formation of heteromeric Kv2 channels in mammalian brain neurons. J Biol Chem 285:15048-15055. CrossRef Medline

Kopp-Scheinpflug C, Fuchs K, Lippe WR, Tempel BL, Rübsamen R (2003) Decreased temporal precision of auditory signaling in Kcnal-null mice: an electrophysiological study in vivo. J Neurosci 23:9199-9207. Medline

Kopp-Scheinpflug C, Steinert JR, Forsythe ID (2011) Modulation and control of synaptic transmission across the MNTB. Hear Res 279:22-31. CrossRef Medline

Li X, Surguchev A, Bian S, Navaratnam D, Santos-Sacchi J (2012) Extracellular chloride regulation of Kv2.1, contributor to the major outward Kv current in mammalian outer hair cells. Am J Physiol Cell Physiol 302: C296-306. CrossRef Medline

Liberman MC (1988) Response properties of cochlear efferent neurons: monaural vs. binaural stimulation and the effects of noise. J Neurophysiol 60:1779-1798. Medline

Liberman MC, Gao WY (1995) Chronic cochlear de-efferentation and susceptibility to permanent acoustic injury. Hear Res 90:158-168. CrossRef Medline

Lima da Costa D, Erre JP, Charlet de Sauvage R, Popelar J, Aran JM (1997) Bioelectrical cochlear noise and its contralateral suppression: relation to background activity of the eighth nerve and effects of sedation and anesthesia. Exp Brain Res 116:259-269. CrossRef Medline
Maison SF, Usubuchi H, Liberman MC (2013) Efferent feedback minimizes cochlear neuropathy from moderate noise exposure. J Neurosci 33:55425552. CrossRef Medline

Malin SA, Nerbonne JM (2002) Delayed rectifier $\mathrm{K}^{+}$currents, $\mathrm{I}_{\mathrm{K}}$, are encoded by Kv2 alpha-subunits and regulate tonic firing in mammalian sympathetic neurons. J Neurosci 22:10094-10105. Medline

Montesinos MS, Chen Z, Young SM Jr (2011) pUNISHER: a high-level expression cassette for use with recombinant viral vectors for rapid and long term in vivo neuronal expression in the CNS. J Neurophysiol 106:32303244. CrossRef Medline

Murakoshi H, Trimmer JS (1999) Identification of the Kv2.1 $\mathrm{K}^{+}$channel as a major component of the delayed rectifier $\mathrm{K}^{+}$current in rat hippocampal neurons. J Neurosci 19:1728-1735. Medline

Postlethwaite M, Hennig MH, Steinert JR, Graham BP, Forsythe ID (2007) Acceleration of AMPA receptor kinetics underlies temperaturedependent changes in synaptic strength at the rat calyx of Held. J Physiol 579:69-84. CrossRef Medline

Rajan R (1988) Effect of electrical stimulation of the crossed olivocochlear bundle on temporary threshold shifts in auditory sensitivity. I. Dependence on electrical stimulation parameters. J Neurophysiol 60:549-568. Medline

Rajan R (2000) Centrifugal pathways protect hearing sensitivity at the cochlea in noisy Rajan that exacerbate the damage induced by loud sound. J Neurosci 20:6684-6693. Medline

Rajan R (2001) Unilateral hearing losses alter loud sound-induced temporary threshold shifts and efferent effects in the normal-hearing ear. J Neurophysiol 85:1257-1269. Medline

Rajan R, Johnstone BM (1988) Binaural acoustic stimulation exercises protective effects at the cochlea that mimic the effects of electrical stimulation of an auditory efferent pathway. Brain Res 459:241-255. CrossRef Medline

Rasband MN (2004) It's “juxta” potassium channel! J Neurosci Res 76:749-757.

Schaeffer DF, Reuss MH, Riemann R, Reuss S (2003) A nitrergic projection from the superior olivary complex to the inferior colliculus of the rat. Hear Res 183:67-72. CrossRef Medline

Steinert JR, Kopp-Scheinpflug C, Baker C, Challiss RA, Mistry R, Haustein MD, Griffin SJ, Tong H, Graham BP, Forsythe ID (2008) Nitric oxide is a volume transmitter regulating postsynaptic excitability at a glutamatergic synapse. Neuron 60:642-656. CrossRef Medline

Steinert JR, Robinson SW, Tong H, Haustein MD, Kopp-Scheinpflug C, Forsythe ID (2011) Nitric oxide is an activity-dependent regulator of target neuron intrinsic excitability. Neuron 71:291-305. CrossRef Medline

Tong H, Steinert JR, Robinson SW, Chernova T, Read DJ, Oliver DL, Forsythe ID (2010) Regulation of Kv channel expression and neuronal excitability in rat medial nucleus of the trapezoid body maintained in organotypic culture. J Physiol 588:1451-1468. CrossRef Medline

Turrigiano G (2011) Too many cooks? Intrinsic and synaptic homeostatic mechanisms in cortical circuit refinement. Annu Rev Neurosci 34:89-103. CrossRef Medline

Wang LY, Gan L, Forsythe ID, Kaczmarek LK (1998) Contribution of the Kv3.1 potassium channel to high-frequency firing in mouse auditory neurones. J Physiol 509:183-194. CrossRef Medline

Wersinger E, Fuchs PA (2011) Modulation of hair cell efferents. Hear Res 279:1-12. CrossRef Medline

Young SM Jr, Neher E (2009) Synaptotagmin has an essential function in synaptic vesicle positioning for synchronous release in addition to its role as a calcium sensor. Neuron 63:482-496. CrossRef Medline 